\title{
LA COMUNIDAD ANDINA, MERCADO ESTRATÉGICO PARA LOS PRODUCTOS AGROINDUSTRIALES PERUANOS
}

La Comunidad Andina, integrada por los países: Bolivia, Colombia, Ecuador, Perú y Venezuela, nació con el nombre de Grupo Andino o Acuerdo de Cartagena, o Acuerdo Subregional de Integración. Su partida de nacimiento fue firmada el 26 de mayo de 1969 por representantes plenipotenciarios de cada uno de los cinco países, a fin de conseguir un desarrollo equilibrado y armónico de los países miembros.

Hasta la fecha, la Comunidad ha logrado la gran parte de sus propósitos; cabe destacar, su entrada a la etapa de unión aduanera, al ponerse en vigencia desde el $1^{\circ}$ de febrero de 1995 el arancel externo común, que significa, que en su territorio aduanero las mercaderías de origen andino circulan libremente sin aranceles ni restricciones de ningún tipo (arancel cero) y los bienes importados de terceros países son gravados con un arancel externo común.

Actualmente, avanza hacia un mercado común, donde circulará libremente no sólo las mercaderías y servicios, sino también el capital y los trabajadores. Se ha iniciado el proceso de liberación de servicios mediante la adopción de políticas en el campo de transporte aéreo, transporte de pasajeros y mercancías por carretera y transporte marítimo. También se ha aprobado y puesto en vigencia un conjunto de normas y regímenes comunes en materia de sanidad, competencia comercial, inversión extranjera y otros.

Desde sus orígenes se establecieron una serie de normas relacionadas con las obligaciones de todos los países miembros de la Comunidad; principalmente, el Programa que concierne con la liberalización y el arancel externo común, la que el Perú incumplió, motivándose su separación temporal de sus derechos, mediante la Decisión $\mathrm{N}^{\circ} 321$; y luego superado dicho impase, mediante la Decisión $\mathrm{N}^{\circ} 414$ del 30 de julio de 1997, se aprueba su reincorporación plena cumpliendo un cronograma de desgravamen arancelarioque inició el $1^{\circ}$ de agosto de $1997 \mathrm{y}$, culminará en diciembre de 2005 .

De acuerdo al Artículo $\mathrm{N}^{\circ} 1$ de la mencionada Decisión, el Programa de desgravamen está comprendido en las subpartidas llamadas NANDINA, que figuran en los Anexos de I al VII.

Hasta la fecha, ya van quedando libres de gravámenes los productos comprendidos entre los Anexos I y IV; entre éstos, se encuentra la relación de productos de agroindustria, con pleno derecho de ingresar al mercado comunitario con arancel cero, sin ninguna restricción, tan igual que los productos de los demás países miembros que gozan de estos beneficios.

¿COMO SE ENCUENTRA EL COMERCIO DEL PERÚ, CON LA COMUNIDAD ANDINA EN LA ACTUALIDAD?

Con respecto al comportamiento del intercambio comercial del Perú con los países de la Comunidad Andina, se ha realizado el análisis respectivo solamente al período que comprende al año 1997, siendo similar el 
comportamiento comercial de los últimos 5 años que se ha revisado.

En el periodo comprendido entre enerosetiembre de 1997, el intercambio comercial del Perú con los países de la Comunidad Andina ascendió a 1.609 millones de dólares, registrando un aumento de $19,8 \%$ ( $\$ 265,6$ millones) comparativamente a lo obtenido en similar periodo del año de 1996. Esta cifra constituye el $14,2 \%$ del valor total comercializado por nuestro país a nivel mundial (Cuadro $\mathrm{N}^{\circ} 1$ ). Fuente: Boletín de Aduanas, publicado por ADEX 1998.

A nivel de países de la Comunidad Andina, se tiene que Colombia y Venezuela concentraron aproximadamente el $71,4 \%$ del comercio efectuado con la subregión (36,9\% y $34,6 \%$ ) del total respectivamente. (Cuadro $\mathrm{N}^{\circ}$ 2).

Conforme se observa en el mismo Cuadro $\mathrm{N}^{\circ} 2$ del intercambio comercial con los países de la Comunidad Andina, el total de la balanza comercial resultó negativa en $\$ 864,2$ millones dólares, monto superior en $\$ 109,1$ millones de dólares respecto al desequilibrio registrado en el periodo enerosetiembre de 1996. Este fenómeno viene repitiéndose desde los periodos anteriores, lo que preocupa seriamente, el bajo volumen de nuestras exportaciones.

A nivel acumulado, las exportaciones mostraron un ligero crecimiento al pasar de \$294,2 millones de dólares a \$372, 4 millones en el periodo enero-setiembre de 1997.

De acuerdo al Cuadro No 3 "Exportaciones a los países de la Comunidad Andina por sectores entre enero-setiembre de 1997", se observa que el $30.06 \%$ corresponde a los productos tradicionales $y$ el 69,94\% a los no tradicionales. De éstos $69,94 \%$, sólo el $6 \%$ representa a la producción agropecuaria, lo que indica un serio descuido de este sector, siendo el Perú un país eminentemente agrícola, desde la época del incanato.

Muchos analistas de la situación crítica del Perú actual aconsejan que el futuro de este país estaría básicamente en el agro, específicamente en la agroindustria porque posee recursos naturales de gran potencialidad en su vasta extensión territorial, con diversidad de climas que privilegian al Perú en comparación con los de otros países.

El problema está en determinar qué productos del sector Agroindustrial se exportan; interesa el volumen, la variedad de los mismos para luego repotenciarlos con una estrategia agresiva, aprovechando el mercado cautivo que ofrece la Comunidad Andina para productos exclusivos y originarios. Además, el futuro del Perú está definitivamente en sus productos agrícolas, específicamente agroindustria, que le permitirá alejarlo de su extrema pobreza y buscar el bienestar de la población en general.

\section{REFLEXIONES SOBRE LA BASE DE LA PRODUCCIÓN AGRICOLA EN EL PERÚ}

El Perú, con su 1'250,000 km², de extensión territorial, tercera en América del Sur, sólo aprovecha el 3,8\% del territorio para cultivo en limpio; $2,1 \%$ para cultivo permanente y $13,9 \%$ para soportar pastos y ganadería. Los antiguos peruanos para superar la deficiencia de recursos de suelo y agua, aprovecharon lo máximo, pues irrigaron y drenaron 700,000 has. de desiertos costeros, manejaron las aves guaneras para fertilizar el arenal, terracearon y regaron mucho más de 1 millón de hectáreas en las montañas para evitar la pérdida del precioso suelo, adaptaron y seleccionaron especies y variedades de plantas para cada piso ecológico, entre 


\section{EXPORTACIONES FOB A LOS PAÍSES DE LA CAN POR SECTORES \\ ENERO - SETIEMBRE 1996 - 1997 \\ (En miles de dólares)}

\begin{tabular}{|c|c|c|c|}
\hline & ENE-SET 96 & ENE-SET 97 & VAR $\%$ \\
\hline INTERCAMBIO COMERCIAL & 1343402,68 & 1608996,07 & 19.77 \\
\hline BALANZA COMERCIAL & $(755072,68)$ & $(864156,94)$ & 14.45 \\
\hline EXPORTACIONES FOB & 294165,00 & 372419,56 & 26.6 \\
\hline Productores Tradicionales & 97641,51 & 111955,10 & 14.66 \\
\hline Agrícolas & 5304,35 & 8256,59 & 55.66 \\
\hline Pesqueros & 17634,38 & 17165,26 & $(2,66)$ \\
\hline Petróleos y Derivados & 1427,31 & 1781,57 & 24.82 \\
\hline Mineros & 73275,47 & 84751,67 & 15.66 \\
\hline Cobre & 37212,70 & 29510,34 & $(20,70)$ \\
\hline Hierro & 21.52 & 21.25 & $(1,25)$ \\
\hline Plata Refinada & 2502,62 & 3355,83 & 34.09 \\
\hline Plomo $1 /$ & 5774,74 & 7496,97 & 29.82 \\
\hline Zinc & 25031,95 & 38521,67 & 53.89 \\
\hline Oro & 2679,34 & 754,30 & $(71,85)$ \\
\hline Estaño & 34.95 & 1011,03 & 2793,03 \\
\hline Resto $2 /$. & 17.65 & 4080,28 & 23014,64 \\
\hline Productos No Tradicionales & 196523,49 & 260464,46 & 32.54 \\
\hline Agropecuario & 15669,53 & 22350,81 & 42.64 \\
\hline Textil & 45946,45 & 67630,08 & 47.19 \\
\hline Pesquero & 14705,53 & 16963,20 & 15.35 \\
\hline Metal - Mecánico & 13368,49 & 15192,52 & 13.64 \\
\hline Químico & 42261,73 & 52448,32 & 24,10 \\
\hline Siderúrgico - Metalúrgico & 46725,23 & 56121,47 & 20.11 \\
\hline Minería no metálica & 7387,43 & 9279,95 & 25.62 \\
\hline Artesanías & 3.29 & 3.47 & 5.53 \\
\hline Madera y Papel & 4296,12 & 7639,08 & 77.81 \\
\hline Piel y Cuero & 475.97 & 864.73 & 81.79 \\
\hline Resto & 5684,01 & 11970,84 & 110.61 \\
\hline Importaciones CIF & 1049237,68 & 1236576,51 & 17.85 \\
\hline Bs. De Consumo No Duradero & 130552,74 & 142687,86 & 9.3 \\
\hline Bs. De Consumo Duradero & 14994,63 & 14883,30 & $(0,74)$ \\
\hline Combustible, Lubricantes y P. Conexos & 523566,06 & 667171,83 & 27.43 \\
\hline Materias Primas y P.I. Para la Agricultur & 82457,45 & 86455,00 & 4.85 \\
\hline Materias Primas y P.I. Para la Industria & 245343,41 & 279374,99 & 13.87 \\
\hline Materiales de Construcción & 33589,58 & 27868,74 & $(17,03)$ \\
\hline Bienes de Capital para la Agricultura & 960.46 & 1621,74 & 68.85 \\
\hline Bienes de Capital para la Industria & 12220,85 & 12796,96 & 4.71 \\
\hline Equipos de Transporte & 5456,65 & 3674,08 & $(32,67)$ \\
\hline Diversos & 95.86 & 42,00 & $(56,19)$ \\
\hline
\end{tabular}

1/. Incluye contenidos de plata. A partir de la fecha se ha hecho esta reclasificación 21. Incluye molibdeno, bismuto y tungsteno, principalmente.

Cobertura : Nacional

Fuente : ADUANAS - Oficina de Sistemas y Estadística. 


\section{BALANZA E INTERCAMBIO COMERCIAL CON LOS PAÍSES DE LA CAN \\ ENERO - SETIEMBRE 1997}

(En miles de dólares)

\begin{tabular}{|l|c|c|c|c|c|}
\hline & BOLIVIA & COLOMBIA & ECUADOR & VENEZUELA & TOTAL \\
\hline Exportaciones FOB & 77659,10 & 113299,31 & 81124,20 & 100336,96 & 372419,56 \\
\hline Importaciones CIF & 113275,98 & 480801,91 & 185096,41 & 457402,21 & 1236576,51 \\
\hline Saldo Balanza Comercial & $(35616,88)$ & $(367502,60)$ & $(103972,21)$ & $(357065,25)$ & $(864156,94)$ \\
\hline Intercambio Comercial & 190935,07 & 594101,21 & 266220,61 & 557739,17 & 1608996,07 \\
\hline
\end{tabular}

\footnotetext{
Cobertura : Nacional

Fuente : Declaraciones Unicas de Importaciones y de Exportación registradas por el SIGAD.

Elaboración : ADUANAS - Oficinas de Sistemas y Estadística.
} 
ENERO - SETIEMBRE 1996-1997

(En miles de dólares)

\begin{tabular}{|c|c|c|c|c|c|c|}
\hline SECTORES ECONÓMICOS & BOLIVIA & COLOMBIA & ECUADOR & VENEZUELA & $\begin{array}{c}\text { TOTAL PAIS } \\
\text { US\$ }\end{array}$ & $\%$ \\
\hline $\begin{array}{l}\text {-OTALES } \\
\text { DRODUCTOS }\end{array}$ & 77659,01 & \multicolumn{2}{|c|}{ DRODUCTOS } & 100336,96 & 372419,56 & 100.00 \\
\hline TRADICIONALES & $1,409,19$ & 39391,73 & 20682,36 & 50501,82 & 111955,10 & 30.06 \\
\hline 1. AGRICOLA & - & 905.33 & 7243,36 & 107.91 & 8256,59 & 2.22 \\
\hline Algodón & - & 881.68 & 13.19 & 107.88 & 1002,75 & 0.27 \\
\hline Azúcar & - & 5.50 & 3196,77 & - & 3202,27 & 0.86 \\
\hline Café & - & - & 2621,67 & - & 2621,67 & 0.70 \\
\hline Resto $1 /$. & - & 18.14 & 1411,74 & 0.02 & 1429,91 & 0.38 \\
\hline 2. PESQUEROS & 30.89 & 6546,70 & 5709,79 & 4877,89 & 17165,26 & 4.61 \\
\hline Harina de Pescado & 30.89 & 5541,71 & 5699,50 & 4811,26 & 16083,35 & 4.32 \\
\hline Aceite de Pescado & - & 1004,99 & 10.30 & 66.63 & 1081,92 & 0.29 \\
\hline $\begin{array}{l}\text { 3. PETROLEO Y DERIVADOS } \\
\text { Crudo }\end{array}$ & 277.50 & 3371,96 & 2181,84 & & 5831,30 & 1.57 \\
\hline Derivados & 277.50 & 3371,96 & 2181,84 & - & 5831,30 & 1.57 \\
\hline 4. MINERO & 1100,80 & 28537,75 & 5547,36 & 45516,03 & 80701,95 & 21.67 \\
\hline Cobre & - & 1199,26 & - & 28311,09 & 29510,34 & 7.92 \\
\hline Hierro & - & 24.25 & - & & 21.25 & 0.01 \\
\hline Plata Refinada & 96.63 & 2692,34 & 419.55 & 150.31 & 3355,83 & 0.90 \\
\hline Plomo $2 \%$ & 0.06 & 3044,22 & 357.13 & 4062,57 & 7496,97 & 2.01 \\
\hline Znc & 252.81 & 20535,59 & 1745,31 & 12987,10 & 38521,67 & 10.34 \\
\hline Oro & 754.30 & - & - & - & 754.30 & 0.20 \\
\hline Estaño & - & 1011,03 & 14.80 & & 1025,83 & 0.28 \\
\hline Resto 3/. & - & 1.06 & 10.58 & 4.11 & 15.75 & 0.00 \\
\hline \multicolumn{7}{|l|}{ PRODUCTOS NO } \\
\hline TRADICIONALES & 76249,91 & 73937,58 & 60441,84 & 49835,14 & 260464,46 & 69.94 \\
\hline Agropecuario & 6994,21 & 5901,05 & 7961,63 & 1493,91 & 22350,81 & 6.00 \\
\hline Textil & 16087,41 & 19412,05 & 17410,02 & 14720,60 & 67630,08 & 18.16 \\
\hline Pesquero & 3383,61 & 11165,18 & 2043,74 & 370.68 & 16963,08 & 4.55 \\
\hline Metal Mecánica & 7795,04 & 2799,22 & 2869,11 & 1729,14 & 15192,52 & 4.08 \\
\hline Químico & 23356,10 & 13614,03 & 11175,49 & 4302,70 & 52448,32 & 14.08 \\
\hline Siderúrgico-Metalúrgico & 9871,62 & 8358,25 & 14041,34 & 23850,25 & 56121,47 & 15.07 \\
\hline Minero no metálico & 1431,35 & 5458,96 & 1474,90 & 914.73 & 9279,95 & 2.49 \\
\hline Artesanales & 0.51 & - & 0.60 & 2.37 & 3.47 & 0.00 \\
\hline Madera y papel & 2591,88 & 2543,95 & 724.35 & 1778,91 & 7639,08 & 2.05 \\
\hline Piel y cueros & 26.52 & 435.30 & 383.34 & 19.57 & 864.73 & 0.23 \\
\hline Varios & 4711,65 & 4249,58 & 2357,32 & 652.29 & 11970,34 & 3.21 \\
\hline
\end{tabular}

1/. Incluye coca y derivados, melazas, lanas y pieles

2 . Incluye contenidos de plata. A partir de la fecha se ha hecho esta reclasificación

3/. Incluye molibdeno, bismuto y tungsteno principalmente.

Cobertura : Nacional

Fuente : Declaraciones Unicas de Exportación registradas por el SIGAD

Elaboración : ADUANAS. Oficinas de Sistemas y Estadísticas 
tantas otras maravillas tecnológicas que hoy ni siquiera podemos reproducir.

Debemos preguntarnos, ¿Con qué se hace agricultura?; pues con suelos, agua, planta, animales, aire y energía solar.

El Ing. Marc Dourojeanni Ricardi, profesor de la Universidad Agraria La Molina, dice: "nuestra independencia alimentaria es un sueño no realizado, debemos tener presente que nuestra escasa base de recursos tierra y la distribución del recurso agua no están realmente bien utilizados; es decir, el recurso natural agua no es escaso en el Perú, pero no está donde la necesitamos más".

El agua abunda en la vertiente amazónica; es escasa en la Sierra, cuyos suelos son los mejores del país pese a la susceptibilidad a la erosión, y en la Costa, aún la escasez es más crítica, donde sin embargo, los arenales regados se pueden transformar en tierras altamente productivas.

El agua constituye un ciclo que el hombre interrumpe con facilidad. Ese ciclo pasa por cuencas, si son maltratadas, ocasionan dos efectos opuestos pero igualmente desastrosos:

Durante la estación de lluvias se generan huaycos, aluviones e inundaciones que destruyen poblados e infraestructuras viales, arrasan tierras de cultivo, matan gente y animales y, durante la estación seca se produce una falta de escurrimiento de agua que también, aniquila por sed a las plantas, animales y humanos. Las cuencas que no han sido vulneradas, en cambio, actúan como válvulas reguladoras y evitan tanto los excesos del verano como la escasez del invierno.

\section{LA FLORA, LA FAUNA Y EL AIRE}

El Perú sin lugar a dudas, es el país privilegiado con mayor diversidad genética que existe en el planeta. La demostración está precisamente en la diversidad de climas. El Perú tiene 96 de las 104 que existen en el mundo. Como resultado de esa diversidad de climas, somos un país que posee el mayor número de especies, variedades de plantas $\mathrm{y}$ animales.

Esa riqueza es una gran ventaja porque nos da la oportunidad de tener plantas y animales útiles adaptados a la realidad ecológica de cada rincón del territorio y a cada requerimiento humano o circunstancia evolutiva de plagas y enfermedades. Los antiguos habitantes de los Andes lo sabían bien, y es por eso, que originaron la mayor concentración mundial de plantas domesticadas que hoy existen.

Nuestra agricultura también depende de lo que sucede con el ozono atmosférico, cuya destrucción repercutirá especialmente en la Sierra y obviamente, también será impactada por cualquier forma de invierno nuclear. El caso patético se puede señalar la desaparición de más de 11.000 millones de $\mathrm{m}^{3}$ de nevadas de las cumbres de Ticlio de la Sierra Central del Perú.

En estos últimos 27 años, (Diario El Comercio, 26 de:junio de 1999), debido al calentamiento global de la tierra, y al incremento de la contaminación ambiental, conforme declara el físico peruano Ramiro Valdivia, el acelerado fenómeno de deshielos se está produciendo en las 20 zonas glaciares de las plantas más elevadas de la Cordillera Occidental y Oriental del país.

Valdivia enfatiza sobre los nevados de Ticlio, que el deshielamiento se ha producido a un promedio de 10 metros cúbicos por año, siendo las causas no sólo el calenta- 
miento global de la tierra, sino la emanación contínua del monóxido de carbono debido al tránsito de unidades pesadas por la zona.

\section{DESCRIPCIÓN DEL SECTOR AGRARIO EXPORTADOR}

La exportación de productos agrícolas en el Perú ha estado basado tradicionalmente en los resultados alcanzados por los sectores azucarero, algodonero y principalmente, cafetaleros, que representan el $83 \%$ de las exportaciones tradicionales. Este comportamiento resulta problemático, sobre todo si se considera que el café es muy sensible a las oscilaciones de precios en el mercado internacional; por lo tanto, el sector agrícola peruano ha iniciado su orientación hacia los productos no tradicionales para penetrar en el mercado mundial.

Los productos no tradicionales pueden ser agrupados según el tipo de producto en los siguientes rubros: hortalizas, frutas, colorantes y condimentos, conservas, jugos, jaleas, plantas naturales, medicinales, etc. El subsector de mayor importancia en la agroindustria de exportación es el de hortalizas frescas y procesados, cuyo producto principal es el espárrago, bajo la forma fresca o conservada, seguida del ajo, la uva y el limón. En la sección comercialización de frutas y hortalizas de la Comunidad Andina se presentan cuadros de volumen de producción, volumen de exportación; así como, los principales mercados de exportación y el análisis de cada producto.

\section{UBICACIÓN GEOGRÁFICA ESTRATÉGICA}

La ubicación geográfica de los países miembros de la Comunidad Andina le otorga al bloque las características de ser una fuente natural entre las regiones de los Andes y la Cuenca Amazónica; así como, con otras partes del mundo a través de los Océanos Pacífico y Atlántico.

Su terreno es la síntesis geográfica de un continente que expande su producción agrícola desde la Costa hasta la Cordillera de los Andes, lo que genera una diversidad de pisos ecológicos que se elevan hasta los $3.500 \mathrm{msnm}$, con una enorme gama de climas y microclimas, conforme hemos señalado en caso específico del Perú, que posee 96 climas diversos (zonas de vida natural), de los 104 climas que existen en el mundo.

Las múltiples combinaciones de temperaturas, precipitaciones y humedad ambiental que caracteriza a los cinco miembros de la Comunidad le permite ofrecer productos en una posición comercial privilegiada.

Los países de la subregión tienen la ventaja de ingresar al hemisferio Norte con productos denominados "Contraestación", no sólo brindado al mundo especies nativas o exóticas, sino también diversas especies tales como espárragos, melón y brócoli; entre otros, que producen y se exportan durante todo el año. Esto implica aprovechar periodos conocidos como "ventanas" en los cuales las frutas y hortalizas de la Comunidad Andina, abastecen la demanda en época de escasez a otros países del mundo.

\section{PRODUCCIÓN Y EXPORTACIÓN DE PRINCIPALES PRODUCTOS DE FRUTAS Y HORTALIZAS DE LA COMUNIDAD ANDINA}

A continuación se presenta cuadros que muestran de algunos productos más importantes a nivel de la Comunidad, indicando el rango de exportación en TM; el total de explotación en miles de dólares, tanto de la producción en fresco como 
procesados y el país miembro exportador. Asimismo el mercado de Exportación.

En todos los cuadros se muestran los volúmenes de producción y exportación y la cantidad en dólares que corresponde al año 1997.

De los 16 productos estudiados y analizados en la tesis doctoral del suscrito, con el título de "Estrategias Competitivas de Productos Agroindustriales Peruanos a Nivel de la Comunidad Andina", solamente se presenta en este artículo algunos de dichos productos, como muestra de la potencialidad productiva del Perú en este sector, frente a los demás países miembros de la Comunidad Andina.

\section{ALCACHOFA}

Es nativa del sur de Europa y Asia Central, contiene inulina que puede ser utilizada como una fuente de energía similar a la del azúcar. Es benéfica para los diabéticos y los hipogrucémicos y para bajar de peso.

\section{CUADRON ${ }^{\circ}$ \\ Volumen de Producción}

\begin{tabular}{|l|c|}
\hline País & Miles de TM. \\
\hline Colombia & 0.3 \\
Ecuador & ND \\
Perú & 3.1 \\
\hline
\end{tabular}

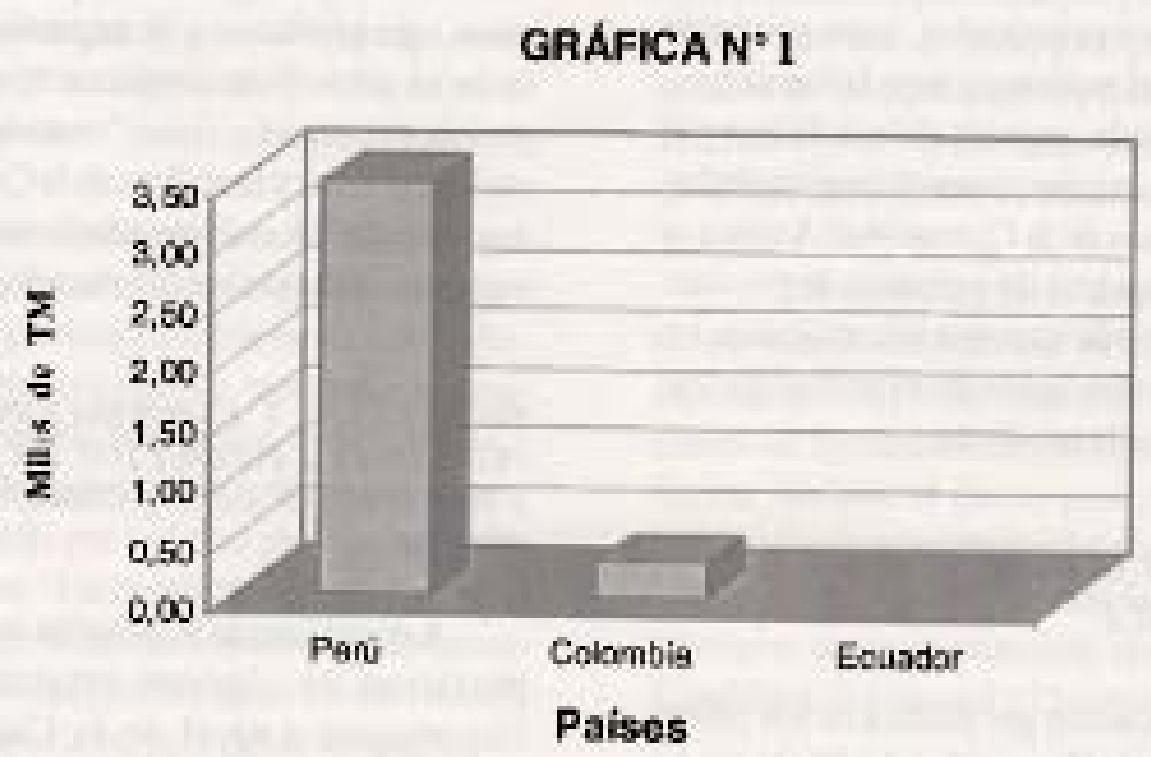




\section{Volumen de Exportaciones}

\begin{tabular}{|c|l|c|}
\hline \multirow{2}{*}{$\begin{array}{c}\text { Rango de Exportaciones } \\
\text { TM }\end{array}$} & \multicolumn{2}{|c|}{ Países Exportadores } \\
\hline & $\begin{array}{l}\text { Frescas o } \\
\text { Refrigeradas }\end{array}$ & $\begin{array}{c}\text { Preparadas o } \\
\text { Conservadas }\end{array}$ \\
\cline { 2 - 3 } & Ecuador & $\begin{array}{c}\text { Ecuador } \\
\text { Colombia }\end{array}$ \\
$5000-10000$ & Colombia & \\
\hline $5000-10000$ & & \\
\hline
\end{tabular}

\section{Mercado de Exportaciones}

(Miles de dólares)

\begin{tabular}{|l|r|}
\hline EE.UU. & 212 \\
Unión Europea & 3 \\
Intracomunidad & 2 \\
Resto del Mundo & 7 \\
\hline
\end{tabular}

GRAFICA N: 2

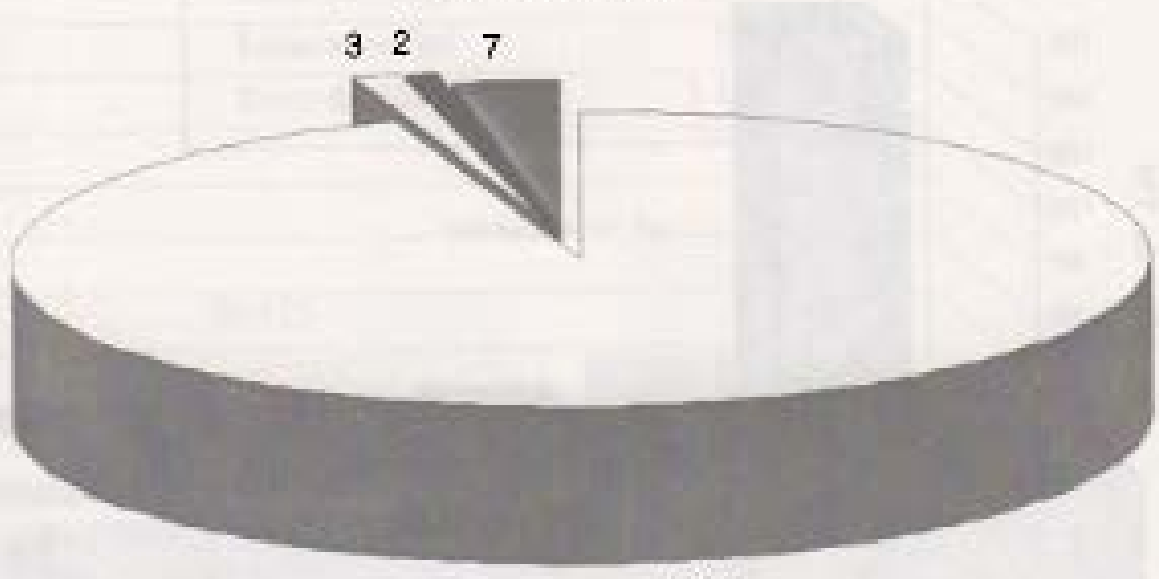

212

Según el cuadro vemos que el mayor productor de Alcachofa es el Perú. Sin embargo, no tiene presencia en el volumen de exportaciones y el gran consumidor es el mercado Norteamericano. 


\section{ESPÁRRAGO}

Este producto es de origen asiático con muy buena adaptación en zonas templadas. Es una hortaliza de tipo perenne de la cual se utiliza el brote tierno denominado Aturión para su consumo. El turión puede ser verde o blanco y contiene la asparagina que tiene gran efecto para depurar la sangre, ayuda a mantener los vasos capilares flexibles y en buen estado.

\section{CUADRON $^{\circ} 5$}

\section{Volumen de Producción}

\begin{tabular}{|l|r|}
\hline País & Miles de TM \\
\hline Colombia & 9.9 \\
Ecuador & 2.0 \\
Perú & 148.5 \\
\hline
\end{tabular}

\section{GRÁFICA N*3}

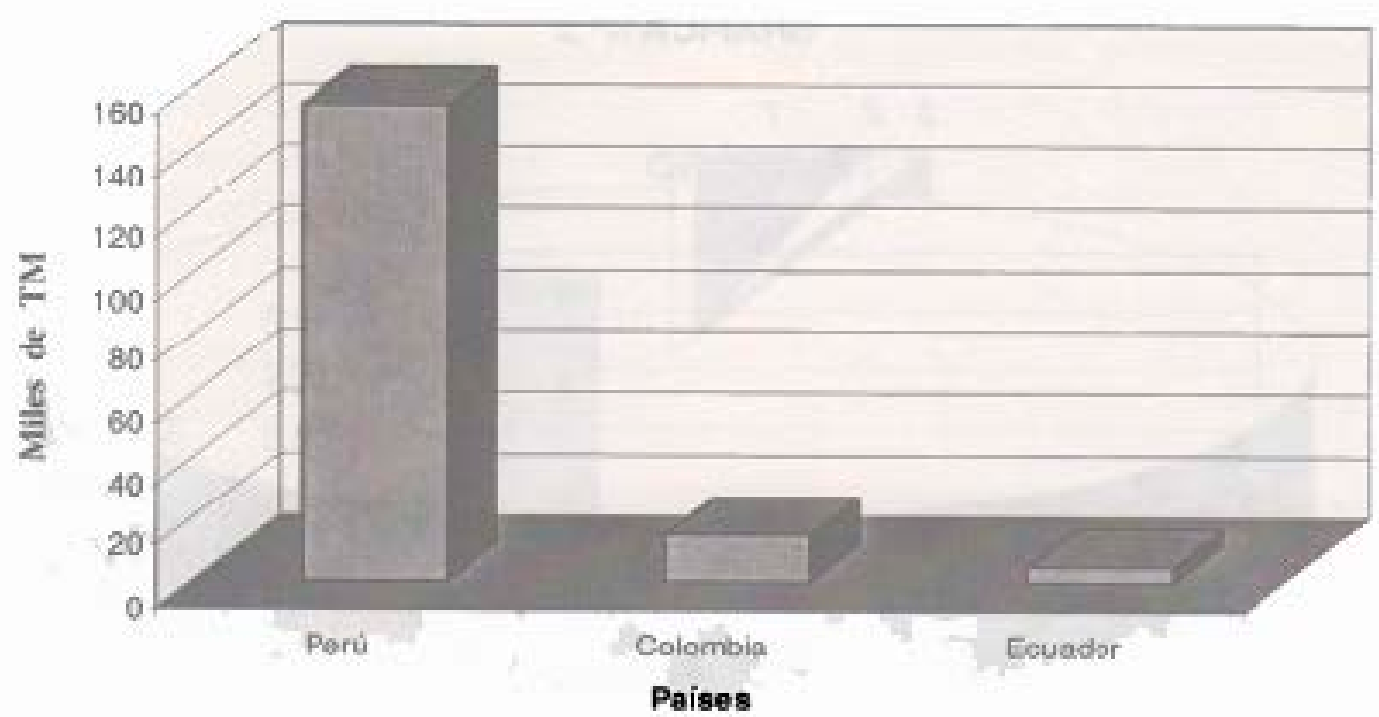


Volumen de Exportación

\begin{tabular}{|c|cc|}
\hline $\begin{array}{c}\text { Rango de Exportaciones } \\
\text { TM }\end{array}$ & \multicolumn{2}{|c|}{ Países Exportadores } \\
\hline & $\begin{array}{c}\text { Frescas o } \\
\text { Refrigerado }\end{array}$ & $\begin{array}{c}\text { Preparadas o } \\
\text { Conservados }\end{array}$ \\
\cline { 2 - 3 } $1-10$ & Ecuador & Colombia \\
$100-1000$ & Colombia & \\
$1000-5000$ & Perú & Perú \\
$10000-20000$ & & \\
Más de 50000 & & \\
\hline
\end{tabular}

Fuente: Comunidad Andina - Secretaría General

\section{Mercados de Exportación}

(Miles de dólares)

\begin{tabular}{|lc|}
\hline EE.UU. & 30522 \\
Unión Europea & 93725 \\
MERCOSUR & 1538 \\
Intracomunidad & 525 \\
Resto del Mundo & 2119 \\
\hline
\end{tabular}

GRÁFICA $N^{\circ} 3 a$

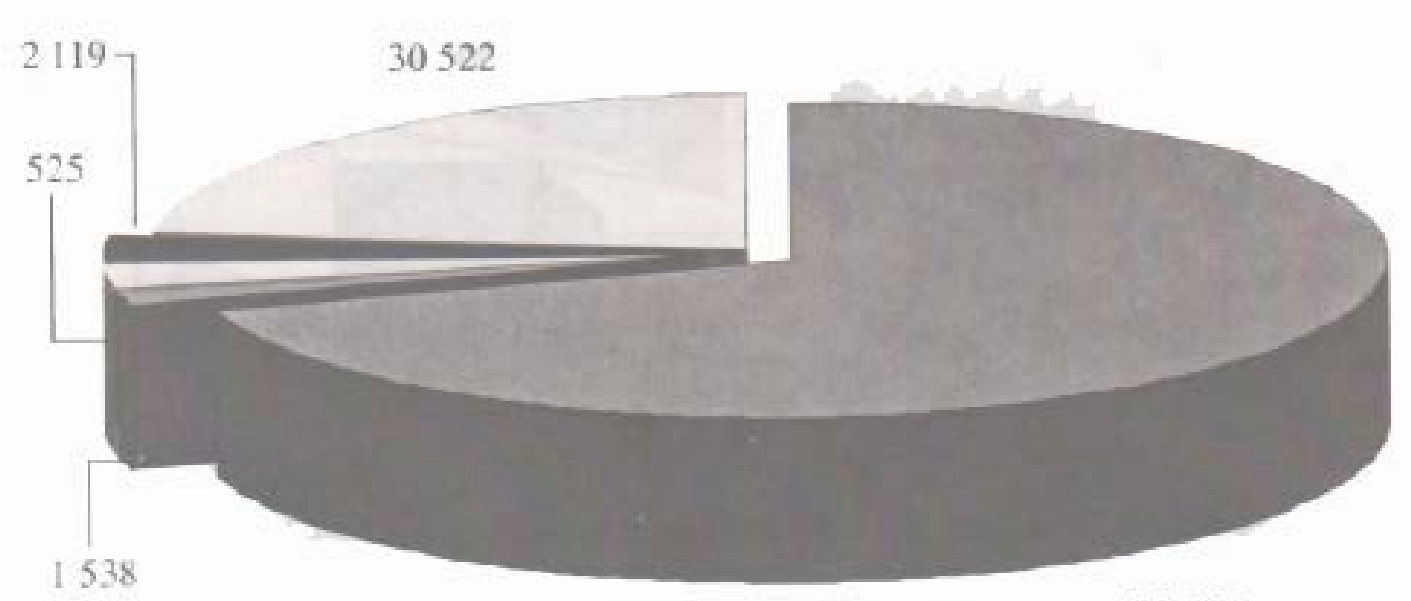

93725 
Según los cuadros, la mayor producción ostenta Perú, casi único en esta parte del continente.

El clima es el principal factor potencial para este producto, que de acuerdo a los datos recogidos de la Comunidad Andina, la siembra de espárragos en el Perú supera los 18,000 hectáreas de terreno.

Los mercados de exportación se concentran entre la Comunidad Europea y
Estadounidense; siendo el comercio intracomunitaria prácticamente mínimo, insignificante.

\section{BRÓCOLI}

Este producto es originario de Asia Menor; es una de la crucíferas que los médicos recomiendan por sus cualidades anticancerosas, sobre todo para proteger de varios tipos de cáncer, entre ellos del colón.

CUADRON $^{\circ} 6$

Volumen de Producción

\begin{tabular}{|l|c|}
\hline País & Miles de TM. \\
\hline Ecuador & 10.4 \\
Perú & 6.0 \\
\hline
\end{tabular}

\section{GRÁFICA N ${ }^{\circ} 4$}

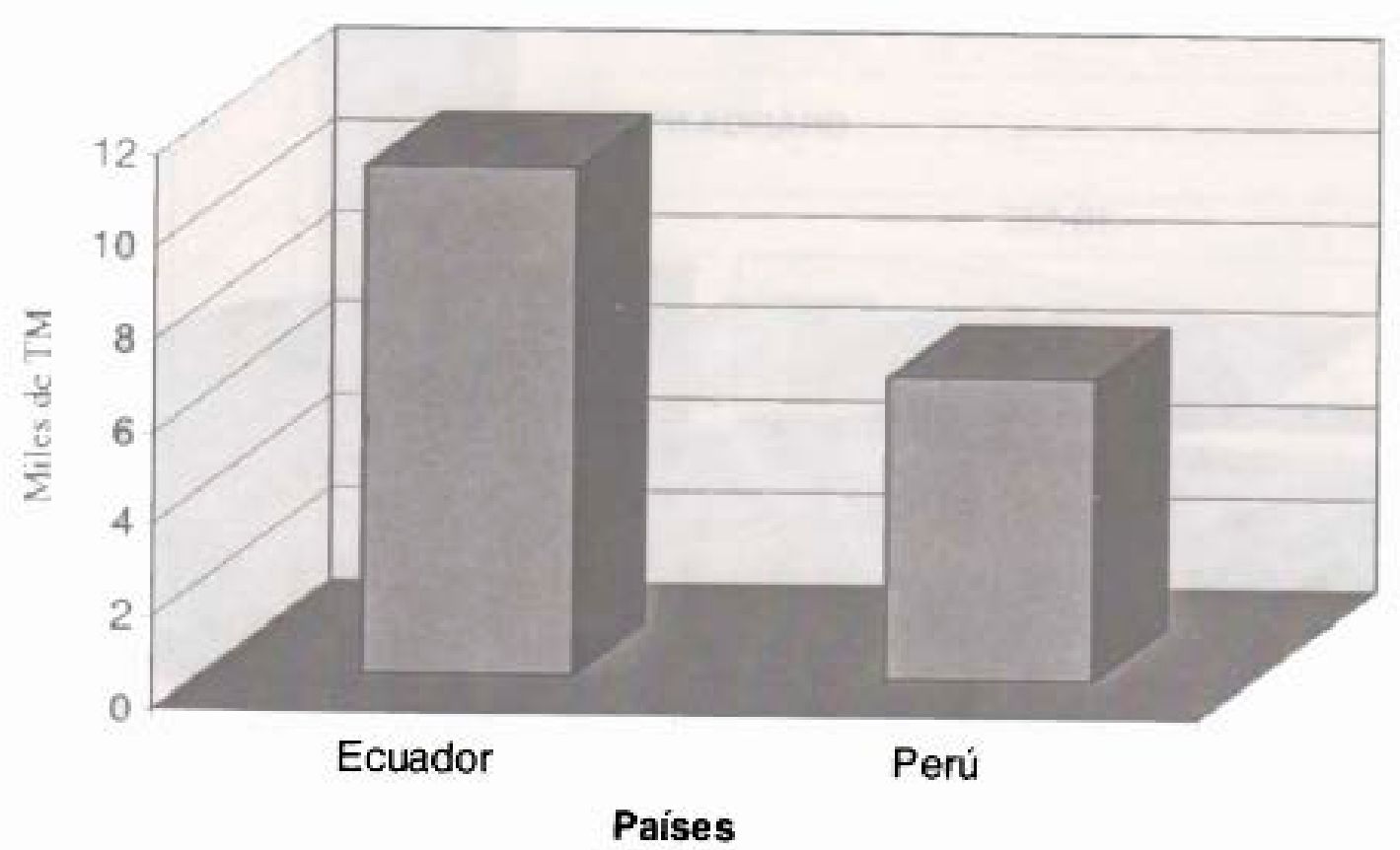


Volumen de Exportaciones

\begin{tabular}{|c|c|}
\hline $\begin{array}{c}\text { Rango de Exportaciones } \\
\text { TM }\end{array}$ & Países Exportadores \\
\hline & Frescas y Refrigeradas \\
\cline { 2 - 2 } $1-10$ & Perú \\
Más de 10000 & Ecuador \\
\hline
\end{tabular}

Fuente: Comunidad Andina - Secretaría General

Mercados de Exportación

(Miles de dólares)

\begin{tabular}{|l|r|}
\hline Unión Europea & 9682 \\
EE.UU & 169 \\
Intracomunidad & 84 \\
Resto del Mundo & 496 \\
\hline
\end{tabular}

\section{GRÁFICA N ${ }^{\circ} 5$}

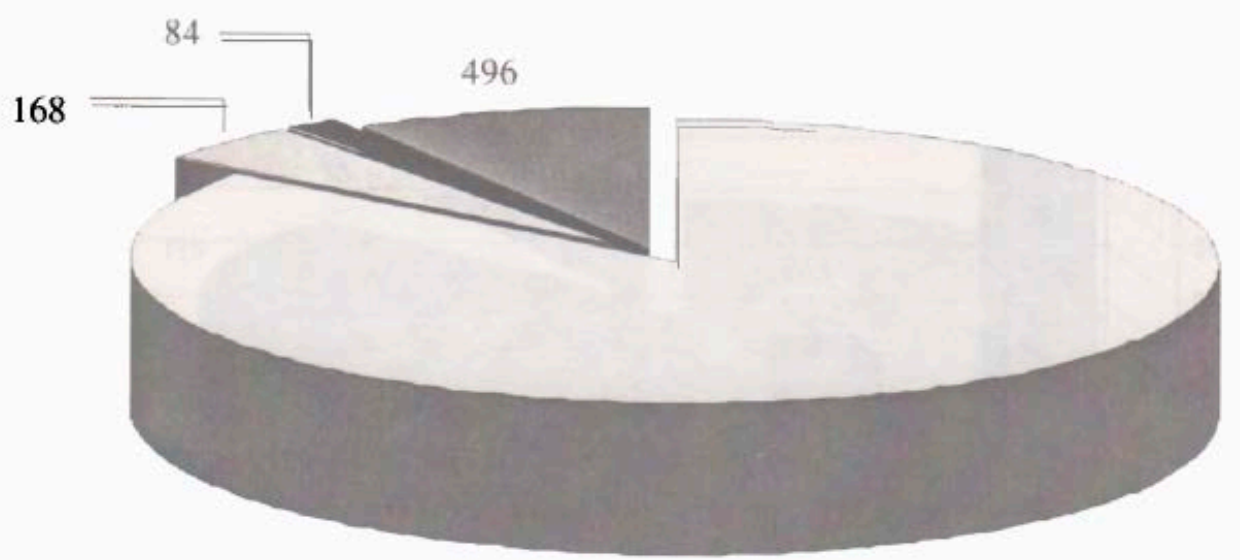

9682 
Entre los cinco países miembros de la Comunidad, sólo Ecuador y Perú producen el Brocoli. En el mercado de exportación, Ecuador tiene gran presencia, siendo el mercado potencial de la Comunidad Europea. El Perú tiene una presencia mınıma con este producto y el comercio intracomunitario, también es insignificante.

\section{AJO}

Es una hortaliza de origen asiático. Ha sido utılizado en la medicina popular desde nace más de 5000 años.
Es una planta bulbosa perteneciente al genero de las cebollas. El bulbo se divide en gajos o dientes, muy aromáticos debido a la presencia de una sustancia sulfurada inodora llamada aliina.

Tiene un gran poder bactericida, capaz de elımınar especies patógenas de la flora intestinal. Su uso es generalizado como condımento principal de las comidas

\section{CUADRON $^{\circ} 7$}

Volumen de Producción

\begin{tabular}{|l|r|}
\hline País & Miles de TM. \\
\hline Bolivia & 6,5 \\
Colombia & 2,4 \\
Ecuador & 2,2 \\
Perú & 41,5 \\
Venezuela & 11,8 \\
\end{tabular}

\section{GRÁFICA N ${ }^{\circ} 6$}

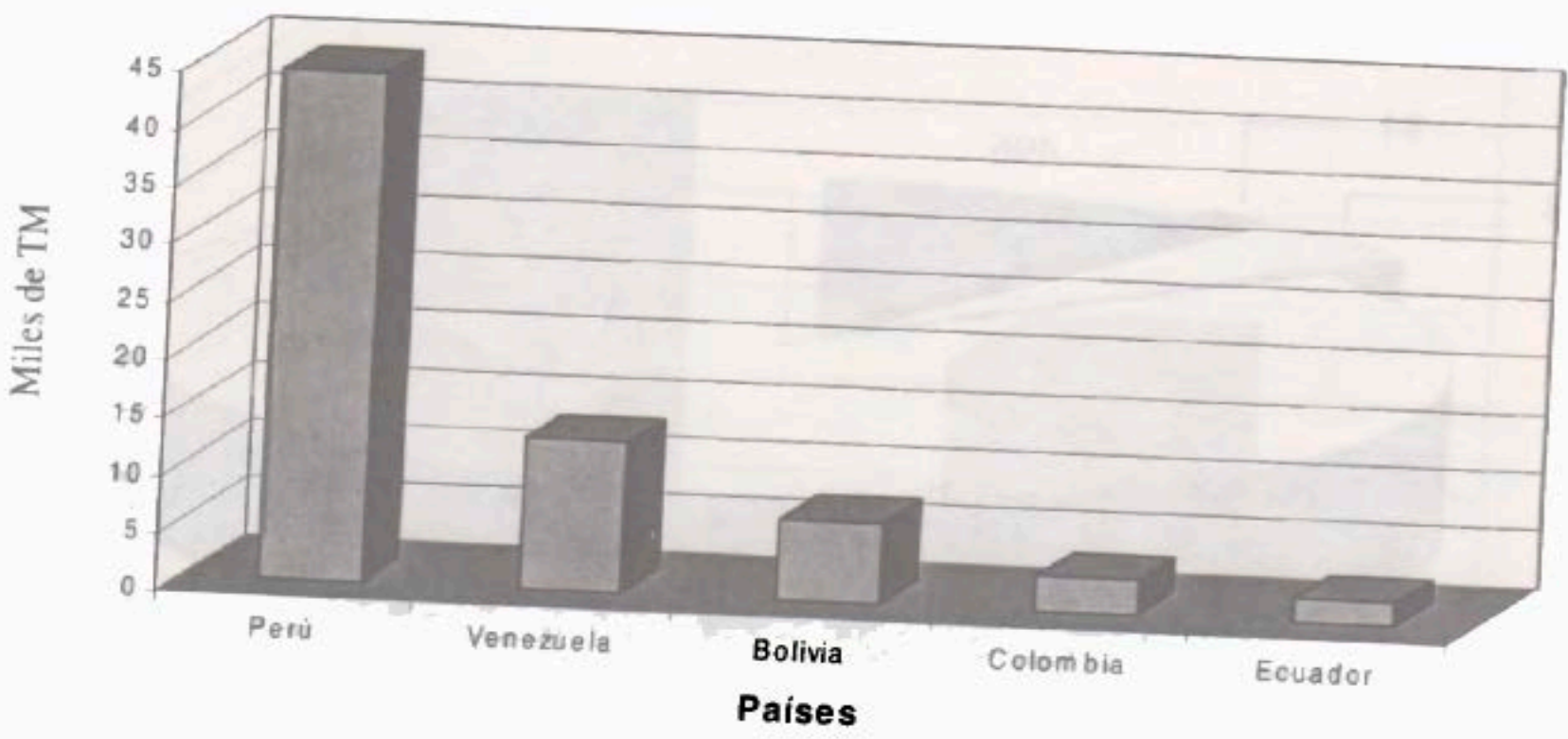


Volumen de Exportación

(TM)

\begin{tabular}{|c|c|c|}
\hline $\begin{array}{c}\text { Rango de Exportaciones } \\
\text { (TM) }\end{array}$ & \multicolumn{2}{|c|}{ Países Exportadores } \\
\hline & $\begin{array}{c}\text { Frescos o } \\
\text { Refrigerados }\end{array}$ & Secos \\
\cline { 2 - 3 } $1-10$ & Venezuela & Bolivia - Colombia \\
$10-100$ & Perú - Venezuela \\
$100-1000$ & Polivia & \\
$1000-5000$ & Perú & \\
\hline
\end{tabular}

Mercado de Exportaciones

(Miles de dólares)

\begin{tabular}{|l|r|}
\hline Intracomunitaria & 803 \\
MERCOSUR & 135 \\
EE.UU & 53 \\
Unión Europea & 15 \\
Resto del Mundo & 76 \\
\end{tabular}

\section{GRÁFICA N ${ }^{\circ} 7$}

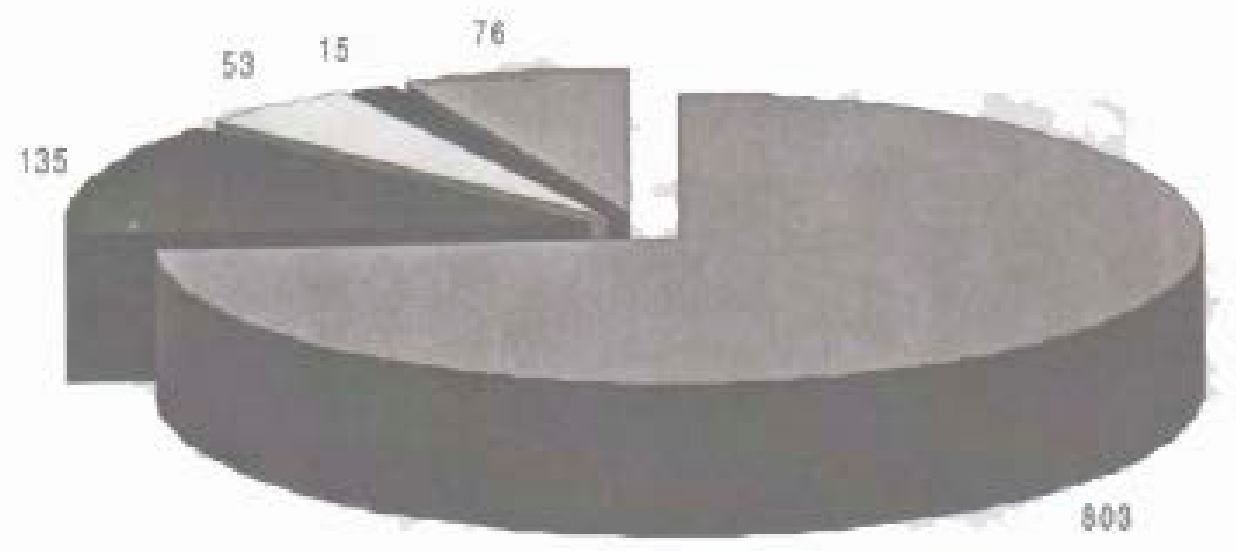


Con la producción y exportación del Ajo, el Perú es líder entre los cinco países miembros de la subregión. El rango de sus exportaciones es la más alta y en cuanto a Mercados de Exportación vemos que este producto es demandado por la misma Comunidad Andina en gran escala; por otro lado, el bloque económico MERCOSUR, integrado por los países de Argentina, Brasil, Uruguay y Paraguay son consumidores del Ajo aunque no en gran proporción. Esto indica, que se abre grandes oportunidades de mercado para el Perú con este producto que tiene extraordinarias cualidades curativas y de uso comestible.

\section{UVA}

(VITIS VINIFERA L.)

Es originaria de la región caucásica. Es una baya que presenta diversas formas, tamaño, color, consistencia y aroma según las variedades.

Contiene potasio, útil por su acción diurética, además de calcio y aminoácidos, entre otros componentes. En algunos centros naturistas se usa la dieta de jugo de uvas, pan y agua mineral para curar enfermedades crónicas, Se le atribuye propiedades diuréticas y hepáticas.

\section{CUADRON $^{\circ} 8$}

Volumen de Producción

\begin{tabular}{|l|r|}
\hline País & Miles de TM. \\
\hline Venezuela & 11,0 \\
Colombia & 16,5 \\
Bolivia & 22,9 \\
Perú & 114,4 \\
\hline
\end{tabular}

GRÁFICA $\mathbf{N}^{\circ} 8$

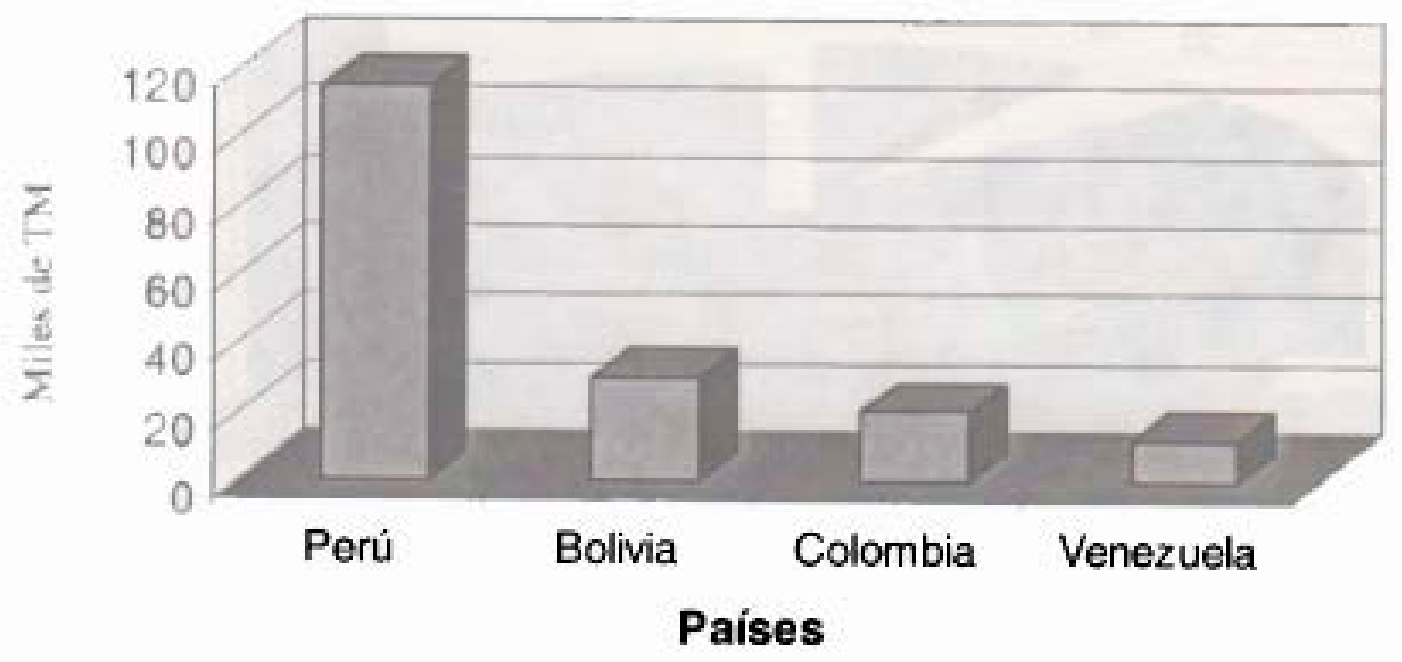


Volumen de Exportación

(TM)

\begin{tabular}{|c|c|}
\hline $\begin{array}{c}\text { Rango de Exportaciones } \\
\text { (TM) }\end{array}$ & Países Exportadores \\
\hline & Frescas \\
\cline { 2 - 2 } $10-100$ & Venezuela \\
$100-1000$ & Colombia \\
$1000-5000$ & Perú \\
& \\
\hline
\end{tabular}

Mercados de Exportación

(Miles de dólares)

\begin{tabular}{|l|r|}
\hline Unión Europea & 1774 \\
Intracomunitaria & 811 \\
EE.UU. & 16 \\
Resto del Mundo & 20 \\
\hline
\end{tabular}

GRÁFICA N ${ }^{\circ} 9$ 
Según los cuadros se observa que el primer productor de la Uva es el Perú con 114,400 TM, los demás países miembros de la Comunidad Andina sumados todos, no llegan ni al 50\% de la producción del Perú.

La uva se exporta en estado fresco y el rango de exportación le corresponde al Perú entre 1,000 a 5,000 TM.

En cuanto al mercado de exportación, es la Comunidad Europea el principal comprador por el monto de 1'774,000 dólares, seguido del mercado intercomunitario por valor de 811,00 dólares.

\section{LMOÓN}

(Cifrus aurantifolia)

El limón es originario del sudeste de Asia. Contiene alto nivel de bioflavonoides y vitamina C. Es recomendado para ayudar a fortalecer los vasos capilares y las células de la piel, los tejidos, las arterias y las venas.

El aceite extraído de la cáscara es usado en gaseosas, productos farmacéuticos y la industria química. La cáscara deshidratada se usa para la fabricación de pectinas y preservantes de alimento.

\section{CUADRON ${ }^{\circ} 9$ \\ Volumen de Producción}

\begin{tabular}{|l|c|}
\hline Países & Miles de TM \\
\hline Ecuador & 14,0 \\
Perú & 325,7 \\
& \\
\hline
\end{tabular}

GRÁFICA ${ }^{\circ} 10$

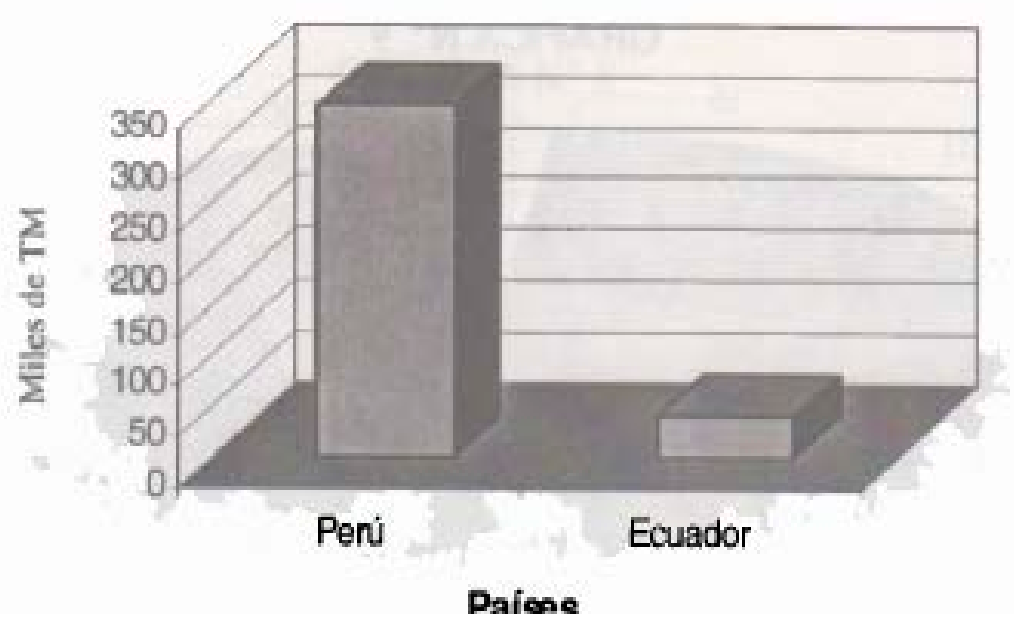


Volumen de Exportación

(TM)

\begin{tabular}{|c|c|c|c|}
\hline $\begin{array}{c}\text { Rango de Exportaciones } \\
\text { (TM) }\end{array}$ & \multicolumn{3}{|c|}{ Países Exportadores } \\
\hline & $\begin{array}{c}\text { Corteza o } \\
\text { Cáscara }\end{array}$ & Jugo & $\begin{array}{c}\text { Aceite } \\
\text { Esencial }\end{array}$ \\
\cline { 2 - 4 } & Venezuela & $\begin{array}{c}\text { Ecuador } \\
\text { Colombia } \\
1-10\end{array}$ & Perú \\
$10-100$ & Venezuela & \\
$100-1000$ & Perú & Perú \\
$1000-5000$ & & & \\
\hline
\end{tabular}

Mercados de Exportación

(Miles de dólares)

\begin{tabular}{|l|r|}
\hline Unión Europea & 4545 \\
EE.UU & 4365 \\
Intracomunitaria & 3 \\
Resto del Mundo & 1243 \\
\hline
\end{tabular}

\section{GRÁFICA ${ }^{\circ} 11$}

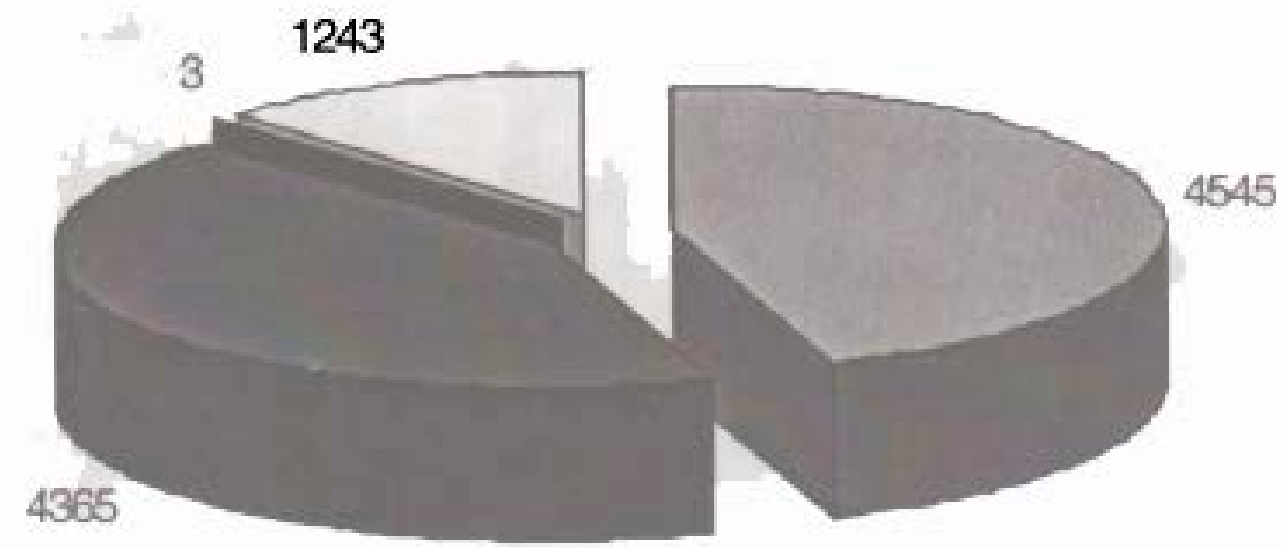


De los cuadros estadísticos sólo 2 países miembros de la Comunidad Andina producen el limón, siendo el Perú el líder absoluto con $325,700 \mathrm{TM}$ de producción y el $2^{\circ}$ país, el Ecuador con 14,000 TM.

El más alto rango de exportación en sus 3 formas es el Perú y el gran comprador es el mercado de la Comunidad Europea, seguido de Estados Unidos. En el mercado intracomunitario no tiene presencia.

\section{ACEITUNA}

(Olea Europa)

El Olivo es nativo de la región del Mediterráneo, Asia Central y varias partes del Africa.
Es una fruta que contiene alto nivel de aceite, muy útil para activar el sistema hepático y biliar, la aceituna negra es la fruta madura tratada con salmuera durante por lo menos tres meses. La aceituna verde es la fruta no madura. Se le atribuye la propiedad de activar sistema hepático y biliar.

Este producto se consume al natural, en ensaladas y el útil para diversas preparaciones de comidas. Las aceitunas rellenas se comen también como aperitivos.

El aceite de oliva tiene gran valor nutritivo y es activador hepático biliar.

\section{CUADRON ${ }^{\circ} 10$}

Volumen de Producción

\begin{tabular}{|l|c|}
\hline Países & Miles de TM \\
\hline Perú (1993) & 16,4 \\
Perú (1994) & 20,6 \\
Perú (1995) & 28,8 \\
Perú (1996) & 27,0 \\
Perú (1997) & 31,1 \\
\hline
\end{tabular}

GRAFICA N ${ }^{\circ} 12$

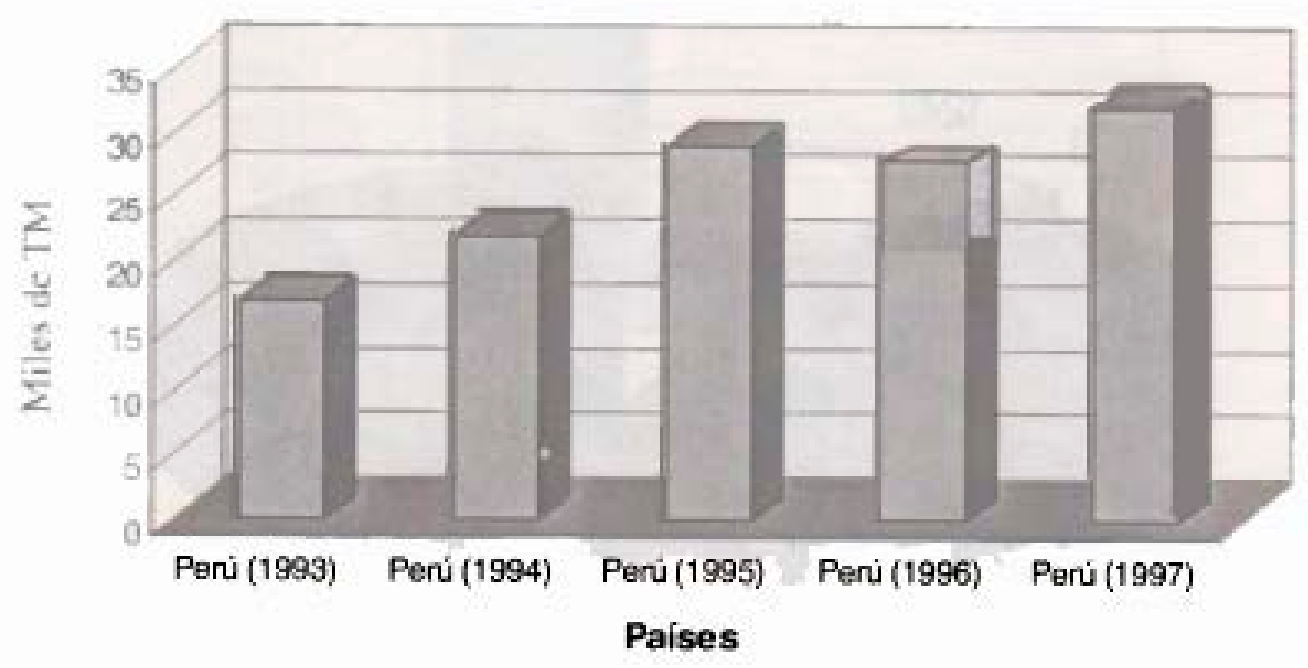


Volumen de Exportación

(TM)

\begin{tabular}{|c|c|c|}
\hline $\begin{array}{c}\text { Rango de Exportaciones } \\
\text { (TM) }\end{array}$ & \multicolumn{2}{|c|}{ Países Exportadores } \\
\hline & $\begin{array}{c}\text { Conservas } \\
\text { provisionalmente }\end{array}$ & $\begin{array}{c}\text { Preparadas o } \\
\text { Conservadas }\end{array}$ \\
\cline { 2 - 3 } & & Perú \\
$100-1000$ & Perú & \\
$1000-5000$ & & \\
\hline
\end{tabular}

Mercados de Exportación

(Miles de dólares)

\begin{tabular}{|l|r|}
\hline MERCOSUR & 5943 \\
EE.UU. & 363 \\
Intracomunitaria & 206 \\
Resto del Mundo & 714 \\
\hline
\end{tabular}

\section{GRAFICO $N^{\circ} 13$}

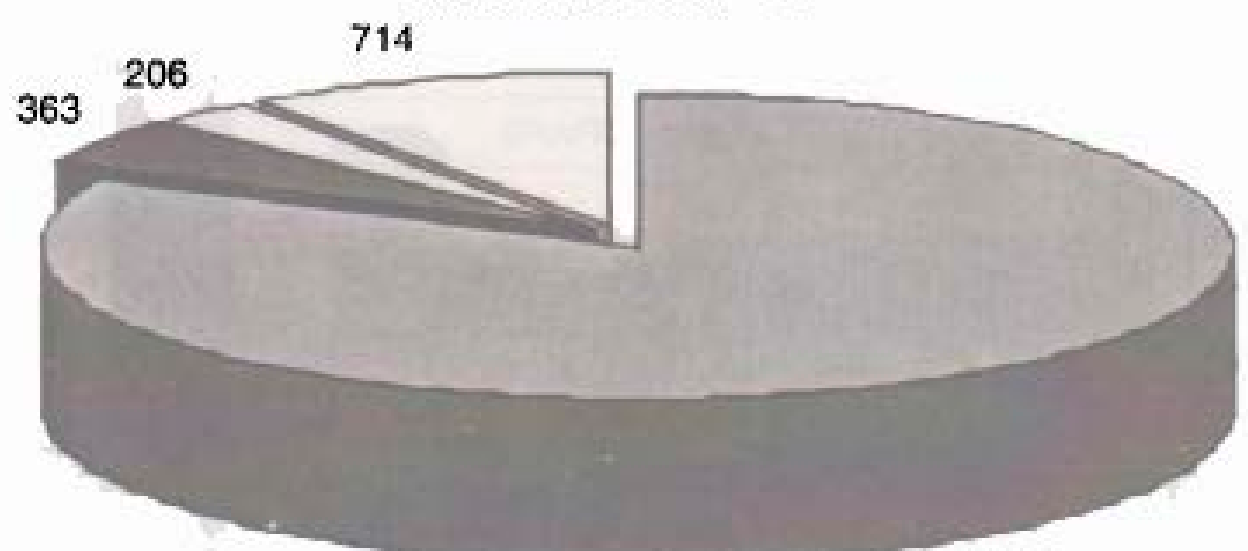

5943 
Según los cuadros estadísticos el Perú es el único productor y exportador de los cinco países de la Comunidad Andina, y en sus dos formas: Conservas provisionalmente y preparados 0 , conservados.

El mercado potencial es MERCOSUR, cuyas compras de este producto asciende a 5'943,000 dólares, seguido de EE.UU. por 363,000 dólares y el consumo intracomunitario sólo por valor de 206.000 dólares.

\section{CEBOLLA \\ (Allium Cepa L.)}

Es un bulbo que fue venerado por los antiguos egipcios y romanos. El jugo de cebolla se utiliza como medio tonificante y digestivo; debido que después de una comida, estimula la acción digestiva y todo el tracto gástrico. Es también un estimulante para el sistema respiratorio y circulatorio.

La utilización del bulbo se realiza tanto en fresca como en la modalidad de procesada o deshidratada.

CUADRON ${ }^{\circ} 11$

Volumen de Producción

\begin{tabular}{|l|c|}
\hline Países & Miles de TM \\
\hline Bolivia & 47,0 \\
Ecuador & 79,0 \\
Venezuela & 136,5 \\
Colombia & 230,0 \\
Perú & 287,7 \\
\hline
\end{tabular}

GRAFICA N ${ }^{\circ} 14$

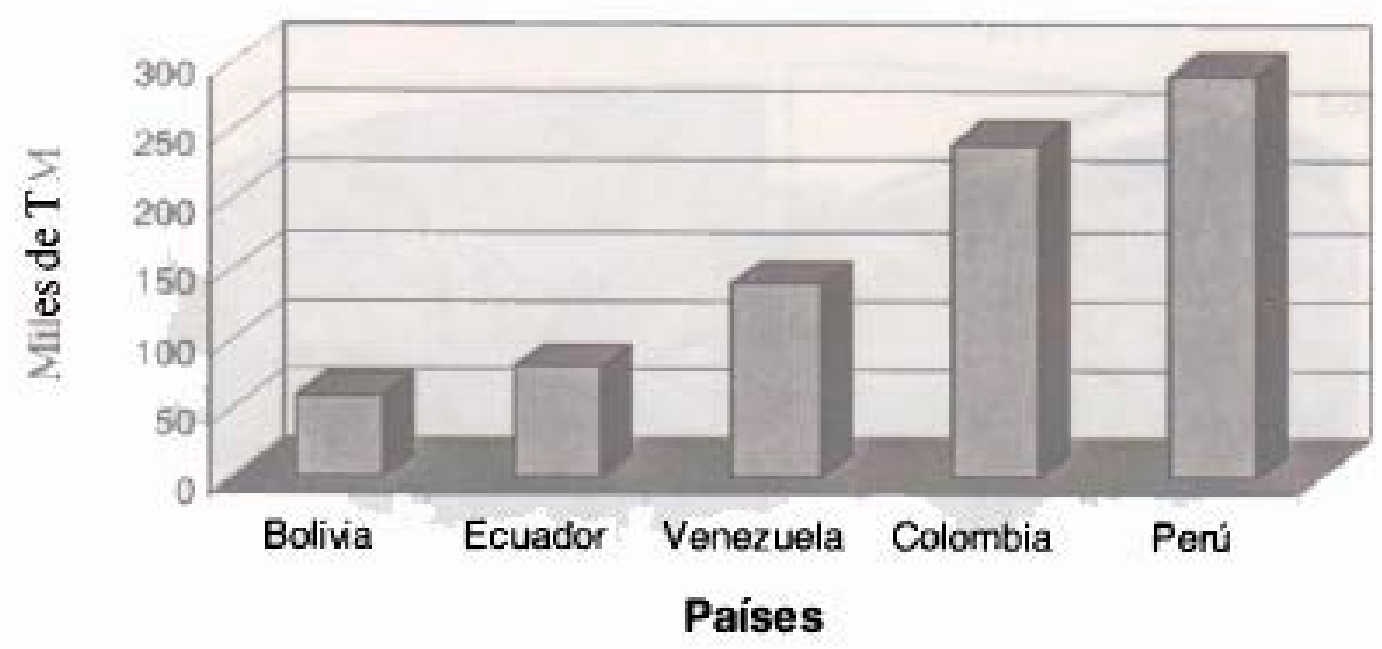


Volumen de Exportación

(TM)

\begin{tabular}{|c|c|c|}
\hline $\begin{array}{c}\text { Rango de Exportaciones } \\
\text { (TM) }\end{array}$ & \multicolumn{2}{|c|}{ Países Exportadores } \\
\hline & $\begin{array}{c}\text { Frescas o } \\
\text { Refrigeradas }\end{array}$ & Secas \\
\cline { 2 - 3 } & & Venezuela \\
$1-10$ & & Colombia \\
$10-100$ & Perú \\
$100-1000$ & Ecuador & \\
$1000-10000$ & Venezuela \\
Más de 10000 & Perú & \\
\hline
\end{tabular}

Mercados de Exportación

(Miles de dólares)

\begin{tabular}{|l|r|}
\hline EE.UU. & 28018 \\
Intracomunitaria & 3284 \\
Unión Europea & 2143 \\
MERCOSUR & 115 \\
Resto del Mundo & 3326 \\
\hline
\end{tabular}

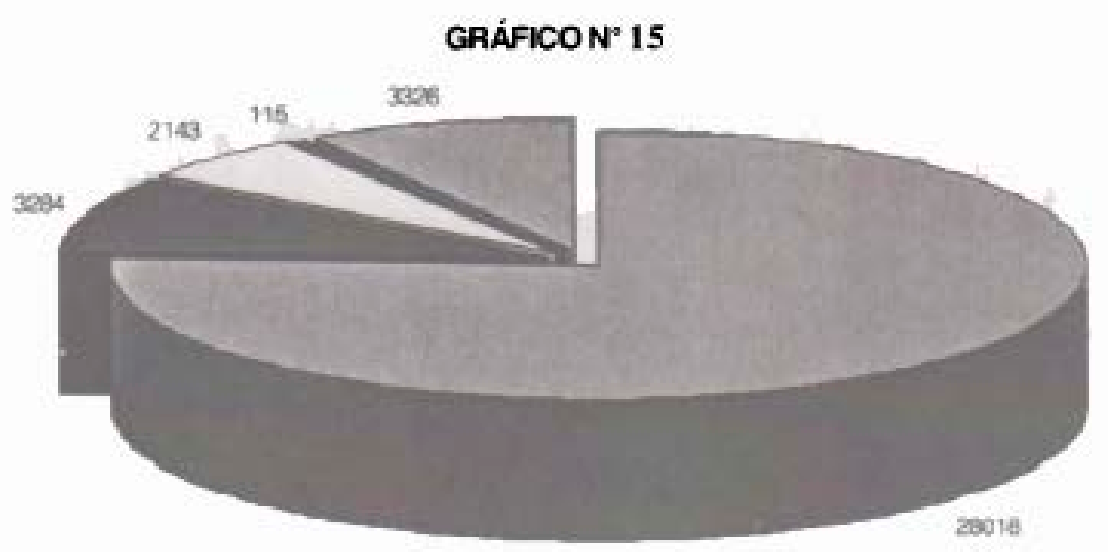


Los cuadros estadísticos nos muestran que el Perú, es el mayor productor entre los miembros de la Comunidad Andina con 287,700 TM durante el año 1997. Le sigue en orden de producción Colombia con $230,000 \mathrm{TM}$ y en tercer lugar, Venezuela con 136,600 TM de producción.

En el rango de exportaciones sigue siendo en el orden de productores el Perú, país que ostenta el mayor volumen de exportación. En cuanto al mercado de exportación es el estadounidense, el gran comprador por valor de $28^{\prime} 018,000$ dólares durante el año 1997.
PAPAYA

(Carica papaya L.)

Fruta oriunda de América Tropical. Tiene alto contenido de vitamina $\mathrm{A}$ y $\mathrm{C}$, rica en calorías. Es favorable para la digestión, se le atribuye propiedades de aumentar la capacidad para coagular la sangre, de laxante y de estimular el apetito.

Se puede consumir sólo o en combinación con otras frutas.

\section{CUADRO N ${ }^{\circ} 12$}

Volumen de Producción

\begin{tabular}{|l|c|}
\hline Países & Miles de TM \\
\hline Ecuador & 13,2 \\
Colombia & 64,0 \\
Venezuela & 80,6 \\
Perú & 146,6 \\
\hline
\end{tabular}

\section{GRÁFICA N ${ }^{\circ} 16$}

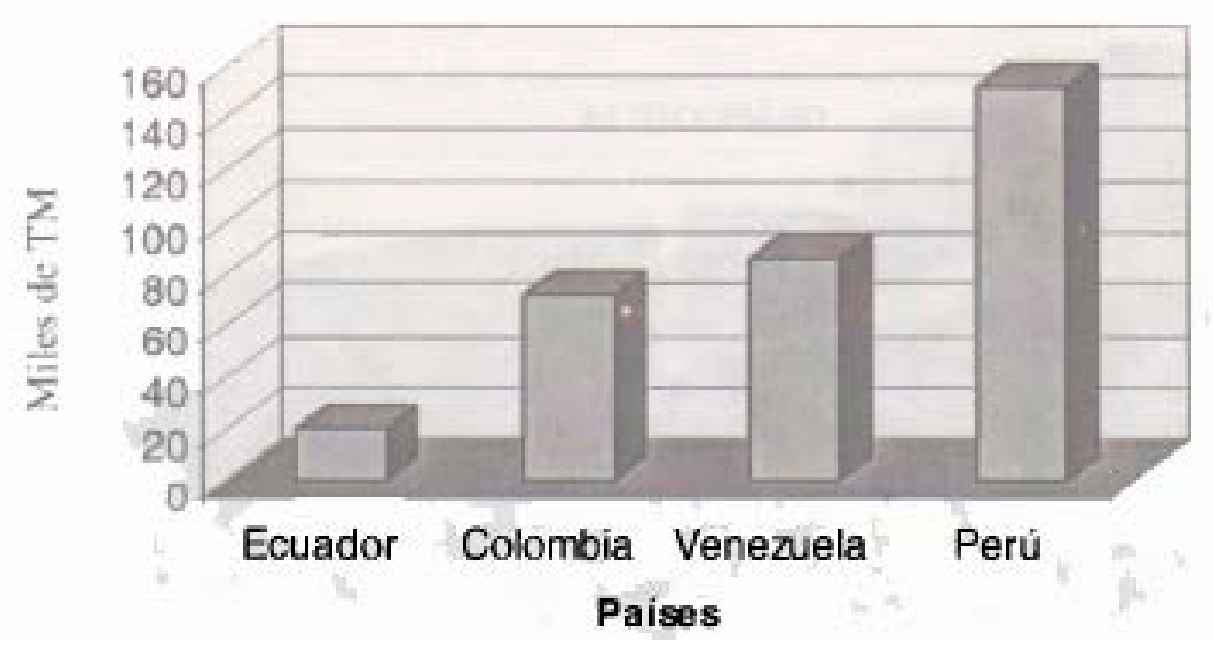


Volumen de Exportación

(TM)

\begin{tabular}{|c|c|c|c|}
\hline $\begin{array}{c}\text { Rango de Exportaciones } \\
\text { (TM) }\end{array}$ & \multicolumn{3}{|c|}{ Países Exportadores } \\
\hline \multirow{2}{*}{$1-10$} & Frescas & $\begin{array}{r}\text { Preparadas o } \\
\text { Conservadas }\end{array}$ & $\begin{array}{c}\text { Jugos sin } \\
\text { Fermentar }\end{array}$ \\
\cline { 2 - 4 } & & Perú & Ecuador \\
$10-100$ & Bolivia & Perú \\
$100-1000$ & Colombia & Venezuela & Colombia \\
& Venezuela & Ecuador & \\
\hline
\end{tabular}

Mercados de Exportación

(Miles de dólares)

\begin{tabular}{|l|r|}
\hline EE.UU. & 150 \\
Unión Europea & 55 \\
Intracomunitaria & 2 \\
Resto del Mundo & 386 \\
\hline
\end{tabular}

GRÁFICAN N 17

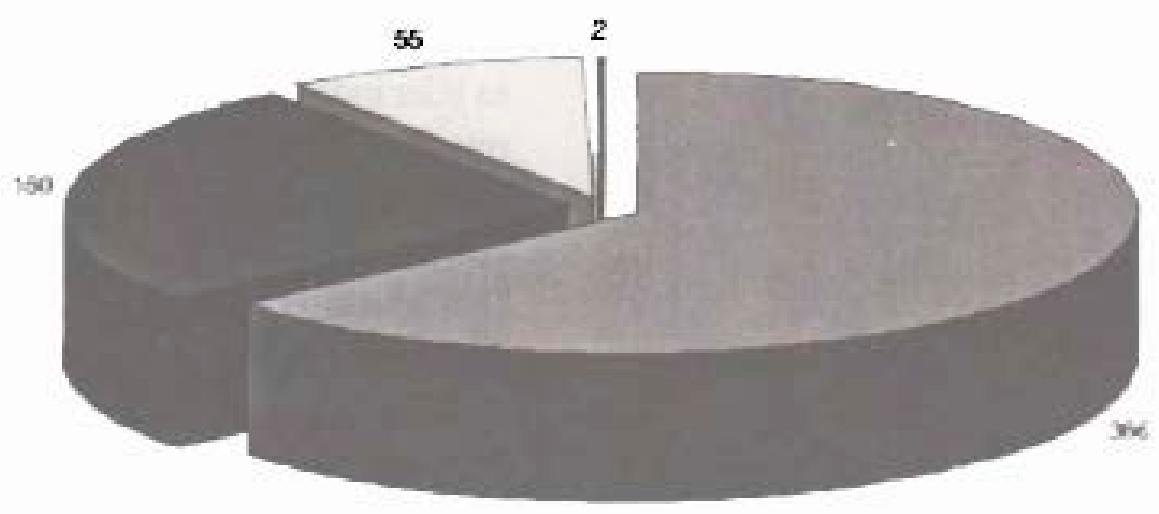


Los cuadros muestran que Perú es el primer productor de papaya con 146,600 TM durante el año 1997, por orden le siguen Venezuela con $80,600 \mathrm{TM}$, Colombia con $64,000 \mathrm{TM}$ de producción y en último lugar, Ecuador con 13,200 TM. Sin embargo, en el rango de exportaciones Venezuela y Ecuador lo hacen entre 100 a 1,000 TM en sus dos formas: frescas y preparadas $o$, conservadas. El Perú aparece en el rango de exportaciones bajo la forma de jugos sin fermentar con mínimo volumen.

El primer pais comprador es Estados Unidos por valor de 150,000 dólares según las estadísticas del año 1997.

\section{CONCLUSIONES}

1. En el territorio aduanero, las mercaderías de origen andino circulan libremente, sin aranceles ni restricciones de ningún tipo (arancel cero) y los bienes importados de terceros países son gravados con un arancel extemo común. Actualmente, avanza hacia un mercado común donde circularán libremente, no sólo las mercaderías y los servicios, sino también el capital y los trabajadores.

En el caso del Perú, según la Decisión No414 el derecho arancel cero está vigente justo para el rubro agroindustria.

2. El Perú fue suspendido temporalmente con respecto a sus obligaciones al Programa de Liberalización y el Arancel Externo Común, mediante la Decisión $\mathrm{N}^{\circ}$ 321 de fecha de agosto de 1992 y en el mes de abril de 1994, se incorpora a la Zona de Libre Comercio mediante la Decisión $N^{\circ}$ 353 y su participación plena se produce el 30 de julio de 1997 mediante la Decisión $N^{\circ} 414$, cuyo cronograma de desgravamen arancelario que inició el $1^{\circ}$ de agosto de 1997 culminará el año 2005.

3. El Perú es un productor potencial, en lo que respecta a productos de frutas y hortalizas; por ejemplo, la alcachofa, el espárrago, el ajo, la uva, el limón, la aceituna, la cebolla, la papaya, la fresa, etc.

Con estos productos, nuestro país es líder indiscutible entre los países de la Comunidad Andina, tanto en volumen de producción como en la exportación. La comercialización de estos productos, casi el 90\% lo realiza entre los mercados de EE.UU. Japón y Europa y un mínimo porcentaje a nivel de la Comunidad Andina, siendo este bloque económico un mercado cautivo, un mercado virgen con Arancel cero para to- 
dos los productos originarios de países miembros.

Entre los productos mencionados que dan el liderazgo al Perú, se encuentra el espárrago que con sus 18.000 hectáreas de sembrío y cosecha, ubica a los agricultores peruanos como los mejores del mundo.

\section{BIBLIOGRAFÍA}

ADUANAS

1999. "Exportación de productos naturales medicinales del Perú", octubre.

AGROINDUSTRIA

1998. Proyecto de Cooperación Empresarial Hispano-Peruano.

BARRÓN ARAOZ. Ricardo

1995. "Marketing Estratégico". Edit. Herrera, Lima.

BARRÓN ARAOZ, Ricardo

XXII Conferencia Interamericana de Contabilidad.

1997. "La competitividad: Estrategia de crecimiento y supervivencia empresarial", Lima.

BOLETÍN DE ADUANAS

1997. Intercambio Comercial. Publicado por ADEX,1998.

BOLETÍN DECOMUNIDAD ANDINA

1998. Integración Andina.

COMUNIDAD ANDINA

1999. ¿Cómo hacer negocios en la Comunidad Andina?, setiembre.

DELGADODELA FLOR, B.FRANCISCO/UGAZ CARO, Roberto

1997. "Características básicas y económicos del cultivo de hierbas de sabor". Instituto Comercio Exterior, Perú.

EMPRESAS EXPORTADORAS DE FRUTAS Y HORTALIZAS

1998. Comunidad Andina.
FRUTAS Y HORTALIZAS ANDINAS PARA EL MUNDO

1999. Comunidad Andina, junio.

GUÍADECOMERCIOE INVERSIÓN

1999. Comunidad Andina, junio.

\section{OBREGÓN VILCHEZ, Lida}

"Especificaciones y diferencias científicas en torno a la Uña de Gato". Instituto de Fitoterapia Americano.

PORIER, Michael E.

1996. "Estrategia competitiva". Edit. Continental, México.

SOLÍs, Ramón

1997. "Producción de maca en la Meseta de Bom Bom". Hospital de Cerro de Pasco. Lima, Perú.

\section{UDAONDODURAN, Miguel}

1996. "Gestión de calidad". Edit. Dias de Santos, Madrid. 